\title{
CONSTRUIR ESPAÇOS NÃO IMAGINADOS INTERPRETANDO A FLUIDEZ DOS TEMPOS
}

\section{To build unimaginable espaces interpreting the flowing of times}

Sérgio Rogério Azevedo Junqueira*

\section{Resumo}

Compreender o significado de ser uma UNIVERSIDADE em contexto de novas e significativas alterações, assumindo, ainda, a sua confessionalidade, é na realidade uma dinâmica exigente, mas perfeitamente possível, caso compreenda-se realizar o processo da missão desta instituição na perspectiva do espaço social que ocupa. Atuar como ENSINO - PESQUISA - EXTENSÃO em diálogo claro, com honestidade científica, é o desafio da UNIVERSIDADE CATÓLICA neste período da história da produção do conhecimento, para tal, orientando uma compreensão inovadora para realizar o anúncio do evangelho neste século XXI.

Palavras-chave: Educação, Ensino Superior, Religião, Pastoral, Universidade Católica.

\section{Abstract}

To understand what to be a university means in the context of new and meaningful changes, assuming its confessional character is in fact a demanding dynamic but quite possible if one intends to implement the university's mission within the perspective of the social set up in which it finds itself. To fulfil the three university's aims of TEACHING, RESEARCH and PUBLIC SERVICES in an honest dialog and with scientific integrity is the challenge of the CATHOLC UNIVERSITY in this period of knowledge production. This requires an innovative approach in order to realise the preaching of the gospel in the 21st century.

Keywords: Education, Higher Learning, Religion, Pastoral, Catholic University.

* Doutor em Ciências da Educação - Programa de Ensino Religioso pela Universidade Pontifícia Salesiana de Roma (Itália), Professor do Programa de Pós-Graduação em Educação da PUCPR, Líder do Grupo de Pesquisa Educação e Religião; Coordenador do Fórum Nacional Permanente do Ensino Religioso (FONAPER), Conselheiro da AECPR.

Endereço: Rua Guabirotuba, n. ${ }^{\circ}$ 158, Prado Velho, Curitiba - PR, CEP 80.215-200.

E-mail: srjunq@uol.com.br 
Procurar expressar o modo de compreender, organizar e propor 0 tempo em que vive, a fim de estabelecer ações pedagógicas responsáveis por um movimento com intensidade e intencionalidade, é o desafio para todos os que atuam em Instituições de Ensino Superior, de maneira especial aos pretendentes no estabelecimento de uma interação entre conceitos e experiências, construtores de projetos que desafiam o mercado ou senso comum do que é a realização de vida nestes fluídos tempos.

Implica dizer a retomada de aspectos presentes em diversas discussões, ou seja, o questionamento sobre a modernidade e a sua pós-situação. A modernidade surge com os trabalhos de sociólogos que, com a intenção de caracterizar as grandes linhas de força, procuraram explicar a descontinuidade em relação a períodos anteriores em que dominavam as tradições e crenças irracionais.

Homens como Marx, Durkeim e Weber perceberam, na modernidade, a emergência de uma nova ordem caracterizada pela presença da indústria, aparentava uma situação social "mais afortunada", pois a racionalização e a produção de saberes inauditos seriam responsáveis pela construção de conhecimentos extraordinários.

A superação de um tempo em que o conhecimento estava baseado na revelação divina, para a racionalização e a difusão dos produtos da atividade científica, tecnológica e administrativa, promoveu, na realidade, uma reorganização social, superando o finalismo religioso responsável por situações discriminatórias na e da sociedade.

Neste contexto, a educação passa a ser percebida como elemento significativo no desenvolvimento das comunidades, existe uma supervalonização de espaços, como a escola, que passa a ser compreendida como um local de ruptura com o meio de origem, para atingir o progresso. Os alunos são vistos como indivíduos que deveriam ser informados de saberes e os professores como mediadores entre os estudantes e os valores universais da verdade, do bem e do belo.

A modernidade é marcada profundamente pelo domínio das ciências, de maneira especial pelo positivismo; o conhecimento é concebido de forma intuitiva, para poder enveredar por uma epistemologia científica comprovada; o método experimental desenvolveu-se, caracterizando uma racionalidade instrumental, isto é, que utiliza critérios de objetividade, de quantificação, de coerência, de reprodutividade e de generalização. A ciência deveria recorrer exclusivamente à observação, à constatação e à experiência, pois o conhecimento não poderia ser encontrado senão na análise de fatos e, para tal, o observador deveria abstrair-se completamente dos elementos subjetivos, cumprindo, desta forma, um dos pré-requisitos essenciais da então ciência, a neutralidade. 
Com certeza, este período da modernidade foi promissor no campo do desenvolvimento de dezenas, para não dizer centenas de teorias, importantes correntes do pensamento e descobertas técnicas, fazendo com que a sociedade presenciasse uma revolução nos diversos campos do conhecimento. Na realidade, assistimos a mundialização destes saberes e progressivamente os benefícios deste processo foram divulgados e utilizados em diferentes situações e regiões do planeta.

Uma característica significativa foi, sem dúvida, a fragmentação deste conhecimento, em que cada uma das ciências modemas capitalizou o saber, dispersos por diferentes competências separadas ou menos irreconciliáveis, e avançou ignorando a fisionomia do todo de que faz parte (MORIN, 1993).

Em contrapartida, um movimento, progressivamente, foi estabelecido, o de reverter tal situação, em que, por exemplo, o sujeito individual não é separado das suas funções sociais. O sujeito é visto como um ator capaz de lutar contra a ordem estabelecida e os determinismos sociais, a fim de subverter incessantemente, ele é, assim, simultaneamente, sujeito da sociedade e sujeito pessoal, de tal forma que um não pode ser absorvido pelo outro sob pena de opressão. Estamos falando da pós-modernidade, em que a sociedade tem a missão de se opor à absorção, não se baseando somente nas pessoas com seus recursos humanos susceptíveis de serem mobilizados.

A confiança em um Deus encontra-se em uma nova leitura, pois o desenvolvimento tecnológico segue o seu curso, entretanto, o ser humano permanece com questões existenciais significativas, donde emerge uma angústia dificilmente dominável. Esta incerteza em encontrar a si mesmo, o seu próprio sentido, o faz procurar aprender, assumir um mundo contingente, infinitamente aberto e indeterminável, demasiadamente complexo, em que cada um tem que gerir as incertezas e a imprevisibilidade. É como se fosse mais seguro dedicar-se a explorar o aleatório, pois combatê-lo demanda desenvolver e aperfeiçoar os mecanismos de interação.

Aparentemente vivemos uma fase de transição. Por um lado, à concepção anterior de um sujeito que adquire conhecimento, que é ensinado e que aprende, começa a emergir a de um sujeito como instrutor do conhecimento, em que se recomendam menos instruções e menos ensino, mais aprendizagem. Propõe-se enfatizar o pensar, refletir, descobrir o mundo, os processos. Após a crença na objetividade do conhecimento, que caracterizou a ciência moderna, a investigação pós-modema pressupõe uma dialética em que o sujeito constrói, a partir de si mesmo, as suas representações sensoriais, perceptíveis, lógicas, em interação permanente com a realidade construída que lhe serve de referência e cuja interpretação permite estabelecer significados.

Compreender uma histónia que está estabelecida a partir de processos de formação, baseado no investigativo, na resignificação de fatos e saberes. Esta- 
mos na presença de uma outra visão epistemológica que resulta não apenas da interação entre os desafios do experimentalismo, do culturalismo, do neopragmatismo, mas a interdisciplinaridade, ou da meta, e a transdisciplinaridade, no sentido de contrariar a excessiva especialização ou a excessiva abrangência, a multidisciplinaridade. Esta complexidade aparece redutoramente concebida em termos de "adesão à mudança", modo maniqueísta de simplificar o que não se entende e/ ou se receia, bem como de idealizar o que se deseja ou se elege como meta inatingível.

Portanto, ao propor discutir o papel da cultura nesta sociedade em transição e a presença das instituições, torna-se constante a interrogação sobre a questão dos valores que atravessam esta realidade?Ou não? O que na realidade é desejado? Indivíduos livres, dóceis, criadores, solidánios, inteligentes, equilibrados, enuditos, sensíveis, adaptados, etc. Na verdade, trata-se simultaneamente de tudo isso. Desenvolver a humanidade, em cada ser humano tal, é, efetivamente, o objetivo complexo proposto por instituições, de maneira especial às relacionadas com a educação.

O modelo pedagógico pós-modemo é concebido como um sistema complexo, tomando em conta as dimensões afetivas, cognitivas, social e ética do indivíduo, bem como os conflitos inerentes às questões culturais e às respectivas negociações. Ele favorecerá uma diversificação das finalidades, a fim de que depois do ser instituído, se passe, progressivamente, a ser educado.

Propor um processo de socialização, quando na realidade existe a tensão com a individualização, implica estabelecer uma comunicação entre as duas características, a fim de favorecer o ser humano como autor de sua história e de sua comunidade. $\mathrm{O}$ que revela a dinâmica do movimento é a força com que este deve ser efetuado.

Na sociedade moderna, ao contránio de outros peńodos, quando existia quase que um determinismo social, foi desenvolvida uma margem de ocupação, profundamente diferente e diversificada, sobretudo, com seres como os humanos, caracterizados pela curiosidade, criatividade, ávidos a conhecer. Contudo, a aprendizagem não se faz sem uma certa dor, mas o prazer em desenvolver o potencial que se encontra neles supera de longe as dificuldades que experimentam.

Neste contexto, é construída uma concepção de Universidade Católica como comunidade acadêmica, que de forma crítica e rigorosa é convocada a contribuir na defesa e desenvolvimento da vida e na compreensão e divulgação da herança cultural, por meio da investigação, do ensino e da extensão.

\section{A fluidez}

O que se percebe é que a compreensão de Universidade é clara em 
nossa legislação e da Pastoral também, que é de evangelizar o meio universitário, buscando formar uma comunidade por meio de ações conjuntas como grupos dos mais diversos membros da academia, como: retiros, celebrações, debates, respeitando a caminhada religiosa de cada um. Para tal, os três elementos de uma Universidade devem ser deflagrados em vista de formarmos de fato uma UNIVERSIDADE CATÓLICA EM PASTORAL: investigação - ensino e extensão.

A Investigação como tarefa privilegiada da Universidade é a de unificar existencialmente no trabalho intelectual duas ordens de realidade. Muito freqüentemente, tende-se a opô-las, como se fossem antitéticas: a investigação da e a certeza de conhecer já a fonte da verdade (JO ÃO PAULO II, 1980).

Parte vital do trabalho da Igreja, por meio de suas Universidades, é o diálogo com as culturas, sobretudo de nosso tempo. Este, por sua vez, nada mais é do que o produzido pelo e para o ser humano.

Portanto, enquanto Católica, a Universidade assume sua identidade, expressando sua inspiração cristã, não apenas de seus dirigentes, mas das orientações que assume diante da comunidade como um todo. Demanda um empenho institucional ao serviço da e na sociedade e, conseqüentemente, sua compreensão da vida.

Para a Universidade Católica significa uma responsabilidade e uma honra consagrar os seus esforços, sem reserva à causa da verdade, que propicie o desenvolvimento e a dignidade das comunidades.

$\mathrm{O}$ encontro entre a proposta do Evangelho e a pluralidade do saber, expresso na imensidade dos campos do conhecimento, que se multiplicam com 0 avanço das descobertas científicas e tecnológicas, exige o desafio de superar as relações egoístas do econômico para o compromisso com a dimensão moral de uma vida digna e plena, existente em todos os âmbitos do planeta, na construção de um mundo melhor.

Continuamente, a Universidade Católica depara-se com o desafio de assumir o seu papel social de uma forma que seja fiel aos seus princípios, por exemplo, ao perseguir o campo da investigação, seus profissionais necessariamente procuram: perseguir a integração do conhecimento, o diálogo entre a fé e a razão, com uma preocupação ética e com a perspectiva teológica.

Portanto, na Universidade Católica, as pesquisas interdisciplinares deverão organizar-se quer nos domínios técnicos, quer na perspectiva das necessidades da Igreja, com o cuidado de evitar a dispersão de esforços e de chegar a resultados que sejam ao mesmo tempo de valor indiscutível no plano universitário e susceptível de servir à comunidade humana e cristã. Isto supõe a investigação nas ciências religiosas e a reabilitação de um diálogo entre a Fé e a cultura humana (ASSOCIAÇÃO BRASILEIRA DE ESCOLAS SUPERIORES CATÓLICAS, 1973, p. 25b). 
Outro elemento de identidade na Universidade, já mencionado, é o ensino, que deve estar intimamente ligado à investigação. De forma sistemática e articulada, o conhecimento transformado em informação, estabelecido de forma orgânica, favorece na e para a formação de novos profissionais competentes, assim como co-responsáveis na participação de uma sociedade solidária e comprometida.

O ensino deve respeitar plenamente a natureza e os métodos próprios de cada disciplina; mas em uma Universidade Católica, este ensino deve estar animado e, além disso, deve aspirar por um espírito cristão real e vivido e por um autêntico respeito à dignidade e liberdade humana. Em sua tarefa de promover a aquisição de conhecimentos, os professores da Universidade Católica devem esforçar-se igualmente para bem orientar os indivíduos na promoção da justiça e da paz no mundo.

A Universidade compromete-se a proporcionar a seus estudantes um ensino de qualidade. $\mathrm{O}$ corpo docente e a autoridade universitária terão, pois, o cuidado constante de submeter a um exame crítico a realização e os métodos de ensino, considerando as inúmeras e importantes pesquisas recentes neste campo (ASSOCIAÇÃO BRASILEIRA DE ESCOLAS SUPERIORES CATÓLICAS, 1973, p. 29).

Finalmente, o terceiro elemento, pertinente à Universidade, é a extensão, espaço em que a instituição coloca-se junto à comunidade como um todo, partilhando e animando tanto dentro da instituição como na região em que está inserida. Por meio da acolhida de eventos, em programas e projetos que permitam a relação entre o saber produzido e o sistematizado, pode haver uma nova visão do ser humano e a promoção da justiça social.

Mediante a investigação, do ensino e da extensão, a Universidade Católica assume sua presença de Igreja com a sociedade no desafio de profissionais que busquem os seus compromissos de serem cada vez mais construtores de uma nova história.

Esta compreensão ocorre em uma fase de transição, em que a sociedade se encontra. Parece existir uma situação de bem-estar mesclada de desconfiança, em que os tempos modernos são concebidos como sólidos e os novos tempos como em estado avançado de desintegração. Portanto, isso provoca o desejo de estruturá-los e solidificá-los.

Um dos sinais é o esforço não apenas em discutir, mas retomar as obrigações éticas, pois parece ter sido profanada a lealdade tradicionalmente conhecida pela sociedade. Entretanto, existe como uma falta de memória que este percurso de flexibilização na realidade não é novo, mas resultado de uma complexa rede de relações sociais estabelecidas por elementos da própria sociedade.

A desintegração social é tanto condição quanto um resultado da nova 
técnica do poder e tem como ferramentas principais o desengajamento e a arte da fuga. Para que o poder tenha liberdade de fluir, o mundo deve estar livre de cercas, barreiras, fronteiras e fortificações. De fato, os poderes globais inclinam-se a desmantelar estas redes em proveito de sua contínua e crescente fluidez, principal fonte de sua força e garantia de sua invencibilidade.

Neste contexto, encontra-se o cidadão como pessoa que tende a buscar o seu próprio bem-estar por meio do bem-estar da cidade. $\mathrm{O}$ indivíduo propõe a individualização, com preocupações centradas em aspectos que desfavorecem a coletividade.

Estamos na realidade tratando de concepções que podem estabelecer ou desagregar relações, ou seja, paradigmas, nada mais do que sistemas estruturados de regras, pressupostos métodos e princípios aceitos, que enquadram a prática de uma comunidade, especificamente a científica. Por sua vez, sofre a interferência do modo como se investiga o contexto, a relação assumida pelo investigador poderá estabelecer visão diferenciada do que é na realidade observada, mobilizando questões como a ontológica, epistemológica e metodológica. Conseqüentemente, teremos focos e enfoques que vão interferir na leitura das relações dentro das propostas para a sociedade em que se vive.

Um dos exercícios foi o modelo fordista, que se tornou quase que a autoconsciência da sociedade moderna. Nesta fase, a administração e trabalho estavam para o bem e o mal, influenciando e "determinando" relações, proposições e mesmo projeto de vida dos cidadãos, de tal forma que o tempo e 0 espaço não foram mais concebidos como estabelecimento de relações, mas conquistas a serem enumeradas, em que era preciso superar resistência, a custos dos próprios cidadãos, favorecendo o estabelecimento de indivíduos, preferencialmente sem história, sem memória.

Para tal, foi acelerado o movimento, a fim de estabelecer maior espaço. As máquinas tornaram-se mais e mais velozes e, nesta corrida, a expansão espacial era o nome do jogo e o espaço seu objetivo; o espaço era o valor; o tempo, a ferramenta. Para maximizar o valor, era necessário afiar os instrumentos. Decretou-se a eliminação do tempo "improdutivo", ocioso e vazio de todos que participassem desta concepção.

A comunidade científica, religiosa e outras áreas responsáveis pelo estabelecimento dos paradigmas propôs teorias, conceitos, logo transformados em publicidade, a fim de que todos os cidadãos se tornassem indivíduos, pensando da mesma forma, pois quem não ocupasse espaço não existia.

A sociedade viu-se no meio de máquinas pesadas, grandes fábricas, milhares de trabalhadores, influenciando inclusive a formação e a articulação das informações nas escolas em todos os seus segmentos. Mas a busca do tempo e do espaço gerou um movimento incontrolável, por meio da rotinização 
do tempo, que passou a ser medido não apenas para contar uma história, mas para verificar o volume de produção.

Conseqüentemente, percebeu-se que para verdadeiramente aumentar a produção e reduzir o tempo, a lógica do processo deveria ser alterada, novos instrumentos deveriam garantir a concretização deste projeto e deveriam ser avaliadas todas as variáveis envolvidas, inclusive o ser humano. Portanto, volume e tamanho deixariam de ser recursos para tornarem-se riscos. A nova instantaneidade do tempo mudou radicalmente a modalidade do convívio humano, os afazeres coletivos.

É interessante ter que conceber uma cultura que passou a ser indiferente à eternidade e que evita a durabilidade, assim como a moral promovida por esta nova forma de articular a sociedade e as relações, em que existe 0 claro desejo de que para viver o presente é necessário esquecer o passado e não acreditar no futuro.

A memória do passado e a confiança do futuro foram, até então, pilares em que se apoiavam as pontes culturais e moral entre a transitoriedade e durabilidade, a mortalidade humana e a imortalidade das realizações humanas, e também entre assumir a responsabilidade e viver o movimento.

Um dos aspectos que com certeza encontra-se em alteração é o trabalho, tornando-se isolado do resto da vida humana, passando a contar apenas os efeitos imediatos, que sejam consumidos no ato, estabelecendo a vida como uma seqüência de episódios, calculados em separados, pois cada um tem seu próprio balanço de perdas e ganhos. A reprodução e o crescimento do capital, dos lucros e os dividendos e a satisfação dos acionistas se tornaram independentes da duração de qualquer comprometimento local com o trabalho.

O cotidiano, mais do que nunca, mostra-nos a vulnerabilidade, precariedade, instabilidade da vida dos cidadãos; mais do que nunca nas diferentes regiões do planeta todos têm em mente o mesmo aspecto da condição humana, experimentando de várias formas e sob nomes diferenciados, a fragilidade do cotidiano.

Condições econômicas e sociais precárias treinam homens e mulheres a perceber o mundo como um engradado abarrotado de objetos desagradáveis, para uma só utilização, inclusive os próprios seres humanos. Cada peça é sobressalente e substituível, é a política da precanização, conduzida por operadores dos mercados de trabalho, que é apoiada e reforçada por políticas adotadas deliberadamente, que favorecem ao enfraquecimento e decomposição dos laços humanos das comunidades e das parcerias, pois é necessário organizar projetos temporais e transitórios por definição, com impacto pragmático.

Conseqüentemente, pessoas inseguras tendem a ser irritáveis; são 
também intolerantes com quaisquer coisas que funcionem como obstáculo a seus desejos; e, como muitos desses desejos serão de qualquer forma frustrada, não há escassez de coisas e pessoas que sirvam de objeto a essa intolerância.

Na realidade, este novo referencial provocou mais do que nunca o uso indiscriminado da palavra "comunidade", pois ela, no sentido sociológico, tornou-se difícil de ser encontrada na vida real, já que homens e mulheres procuram grupos de que possam fazer parte, com certeza e para sempre, em um mundo em que tudo o mais se desloca e muda, em que nada mais é certo.

Neste contexto, encontram-se, de um lado, uma tradição muitas vezes secular e, de outro, uma produção de origem recente, destinada ao consumo de curto prazo. Caso tomemos as palavras "cultura" e "civilização" como uma "totalidade" complexa que compreende os conhecimentos, crenças, artes, leis, moral, os costumes e qualquer outra capacidade dos hábitos adquiridos pelo ser humano enquanto membro da sociedade, ou seja, o orientador da mesma, sem a qual os seus membros não saberiam de onde vêm nem como deveriam comportar-se.

Considera-se a tradição como o que persiste de um passado, no presente em que ela é transmitida. Presente, em que ela continua agindo e sendo aceita pelos que a recebem e que, por sua vez, continuarão a transmiti-la ao longo das gerações. Cria-se, então, a questão: como alimentar uma tradição em uma estrutura em que é proposto assumirmos um esquema de descartabilidade?

Ao longo do processo de globalização são colocadas questões que envolvem a cultura em um espaço aberto entre as culturas e a indústria, entre o local e o global, entre a relação de passado e a inovação contínua do presente-futuro.

Existe o dilema, ou pelo menos o sentimento, de que modernização levará progressivamente as culturas do mundo inteiro a convergir em direção a um modelo único, promovendo uma espécie de saudosismo de ver a diversidade das raças fundir-se pela mestiçagem em um cinzento morno.

A flexibilidade e a agilidade motora e intelectual da espécie humana permitiram que as pessoas se adaptassem às variações mais sutis do ambiente, formando um conjunto genético e mantendo sua unidade biológica. Os jogos, as técnicas, os hábitos alimentares, a música, a dança, as línguas, as práticas, relacionadas com as dimensões mágicas e religiosas, se diversificaram progressivamente, multiplicadas pela inventividade própria dos humanos e à extrema diversidade de seu habitat.

Neste contexto é que precisamos recordar que se a globalização dos fluxos culturais tem apenas algumas dezenas de anos de idade, suas origens nos avanços e recursos da tecnologia das trocas e das comunicações remon- 
tam a mais alta Antigüidade. Esta tecnologia está no centro das dinâmicas de contatos entre culturas diversas, das inovações das técnicas do multilingüismo, do pluralismo cultural, dos conflitos e até da exterminação dos povos minoritários e de sua cultura. Entre o processo de articulação das culturas e a destruição ou substituição das mesmas foi e é o resultado constante de interesses dos que desafiam o direito da diversidade em um desejo contínuo de homogeneização cultural.

A promoção de idéias, das escolhas ideológicas, a propaganda política, a divulgação de informações, verdadeiras ou mentirosas, passam hoje mais do que nunca pela mídia, pois para conservar a identidade, os grupos e as nações devem saber manter, cultivar, renovar o seu patrimônio, mesmo em contexto nem sempre acolhedor e justo. A proteção e valonização do patrimônio, bem como o político educacional soa continuamente confrontado ao particularismo das culturas da tradição. Somente a noção de cultura consegue dar a chave para decifrar os fatos da globalização dos mercados culturais, contextualizando-os, revelando a ilusão de extrair o mercado e a sociedade, nos quais eles estão encaixados e a considerá-los isoladamente, como um sistema fechado, totalizante, auto-suficiente e determinante.

Somos desafiados a procurar um mundo em equilíbrio, superando a cisão que a classe dominante fez e faz entre progresso e desenvolvimento, entendido esse último como altos índices de rendimento dos fatores de produção, isto é, os recursos naturais, o capital e o trabalho. Por progresso, devese entender o uso ético dos resultados da ação humana. Desta forma, saberemos articular o papel da cultura das diferentes comunidades para o exercício da cidadania. Neste contexto encontram-se as Universidades Católicas.

\section{A cultura no espaço pedagógico}

Desde a sua origem, a universidade se autodefine como uma Comunidade de mestres e discípulos, irmanados na busca da verdade.

A palavra comunidade, ou comum unidade, é significativa e traz implicações importantes para a vida universitária. O termo irmanado dá sentido à relação professor-aluno: irmãos mais vividos e experientes, com irmãos mais novos, mas sempre irmãos.

O espírito desse relacionamento deverá garantir sempre relações mais interativas no rigor da construção do conhecimento bem fundamentado, e da vivência íntegra e compartilhada na busca da verdade (JULATTO, 1998).

A universidade como geradora do conhecimento, em um país como o Brasil, tem o grande compromisso social, perante a sociedade, de torná-lo disponível a todos os cidadãos. 
O formando de uma Universidade Católica deveria carregar em sua vida e ações profissionais aquilo que a Instituição foi capaz de fazê-lo vivenciar e assimilar. A sua atuação, nas diversas esferas do mundo social, assumindo diferentes papéis, sendo responsável pela construção quer do individual quer do coletivo, é fundamental para que os valores sejam transmitidos e a cultura preservada. Por sua própria natureza, a Universidade apresenta-se com uma função bidimensional, ou seja, lhe são próprias à produção e à transmissão do conhecimento, por meio do ensino, pesquisa e extensão. Por outro lado, incumbe-lhe formar homens e mulheres profissionais competentes, éticos, responsáveis, comprometidos e solidários.

Como Universidade, por natureza, o lugar de encontro dos diferentes ramos do saber humano, em um esforço de confrontação e enriquecimento recíproco, a Universidade Católica deverá trazer para esta tarefa de síntese e integração a luz da mensagem cristã. Tal procura supõe, em primeiro lugar, uma reflexão crítica sobre os fundamentos epistemológicos e os postulados, sobre os quais se apóiam os métodos das ciências. Esta reflexão é a única capaz de situar cada disciplina no seu devido lugar e avaliar a importância das suas aquisições. Pelo esforço de síntese, sempre inacabado, a Universidade Católica mostrará de maneira especial que não existe nenhuma incompatibilidade entre a ciência e a fé, e que pelo contrário, ambas constituem maneiras diferentes de aproximação da Verdade única, no seio da qual se encontram, sem prejuízo para a identidade de cada uma (ASSOCIAÇÃO BRASILEIRA DE ESCOLAS SUPERIORES CATÓLICAS, 1973, n.ํㅜ 3).

Portanto, aprender a conhecer significa ser capaz de estabelecer pontes entre os diferentes saberes, entre esses e seus significados para a nossa vida quotidiana. Esta abordagem transdisciplinar será o complemento indispensável do procedimento disciplinar, pois ela conduzirá ao surgimento de seres continuamente religados, capazes de se adaptarem às exigências de uma história com variáveis tão instáveis como as enfrentadas neste período contemporâneo de uma aparente fluidez das relações.

É preciso superar a concepção de que viver em conjunto significa apenas tolerar as diferenças de opiniões, cor e crenças dos outros, submissão às exigências dos poderes, navegar entre os meandros de incontáveis conflitos, separar definitivamente a vida interior da vida exterior. A atitude transcultural é transreligiosa, transpolítica e transnacional e pode ser aprendida, pois ela é inédita, na medida em que em cada ser existe um algo sagrado, intangível.

A partilha universal do conhecimento não pode ocorrer sem o surgimento de uma nova tolerância, fundamentada em uma atitude transdisciplinar, que implica pôr em prática uma visão transcultural, transreligiosa e transnacional, decorrendo daí a relação direta entre paz e interdisciplinaridade. 
Esta nova missão de compreender a comunicação entre os grupos demandará muito mais do que discursos, mas há ações concretas e a esperança de estabelecer novos processos de formação em todos os campos.

Recordemos que houve um tempo em que os dinossauros eram imbatíveis, sua força incomparável, mas mudou o mundo, estes animais não souberam se adaptar às novas condições e desapareceram. O mesmo pode estar acontecendo com diversas instituições em nosso dia-a-dia, seu modelo está também tão robusto, mas ficaram pesadas e pouco flexíveis, não conseguindo adaptar-se agilmente aos novos tempos e não saberão sobreviver a tempos futuros, quando as condições se distanciarem ainda mais daquela na qual foram criadas.

Estamos em tempos em que uma significativa tendência está afetando as diferentes formas de informação e formação; é a interdependência global; fronteiras que nos dividiram por vários séculos estão desaparecendo; algumas dessas são nacionais, mas as mais impressionantes são as normativas, culturais e econômicas, que também estão sendo reduzidas ou desaparecidas, provocando uma maior movimentação de pessoas, bens e serviços, idéias e informações.

Um dos espaços privilegiados é com certeza o do Ensino Superior, organizado para promover, pela pesquisa, o progresso da ciência, transmitindo, pelo ensino, conhecimentos que enriqueçam ou desenvolvam o espírito e que sejam úteis à vida. O Ensino Superior forma especialistas em todos os ramos da cultura, das letras e das artes, por meio de cursos, sínteses, conferências, palestras (Decreto 6.283 de 25 de janeiro de 1934, artigo 2. ${ }^{\circ}$ ). Ou mais recentemente, como previsto no artigo quarenta e três da atual LDB (9394/96), afirma que a educação superior tem por finalidade estimular a criação cultural e o desenvolvimento do espírito científico e do pensamento reflexivo, formando diplomados nas diferentes áreas de conhecimento, aptos para a inserção em setores profissionais e para a participação na sociedade brasileira, e colaborar em sua formação contínua. Incentiva, ainda, o trabalho de pesquisa e investigação científica, visando ao desenvolvimento da ciência, da tecnologia, da criação, a difusão da cultura, desse modo, desenvolve o entendimento do ser humano e do meio em que vive.

Promove, também, a divulgação de conhecimentos culturais, científicos e técnicos que constituem patrimônio da humanidade e comunica o saber por meio do ensino, de publicações ou de outras formas de comunicação, suscitando o desejo perante o aperfeiçoamento cultural e profissional e possibilitando a correspondente concretização, integrando os conhecimentos que vão sendo adquiridos numa estrutura intelectual sistematizadora do conhecimento de cada geração. Estimula o conceito dos problemas do mundo presente, em particular os nacionais e regionais, prestando serviços especializados à comunidade e estabelecendo, com esta, uma relação de reciprocidade. 
Assim como, promove a extensão, aberta à participação da população, visando à difusão das conquistas e benefícios resultantes da criação cultural e da pesquisa científica e tecnológica, geradas nas instituições de ensino superior. Existe o desafio de alcançarmos, portanto, uma educação dialógica que supere as concepções educativas construtivistas e da qual deve partir qualquer ação educativa com uma firme posição por uma educação que tenha como objetivo a igualdade, a solidariedade, a aprendizagem instrumental de conhecimentos e habilidades e a transformação.

Não é possível negar que a era da industrialização está sendo substituída pela era do conhecimento e da informação, sem que, contudo, possa deixar de reconhecer o perigo do que já se chama fase da informática e antever as suas temíveis conseqüências de exclusão social. Portanto, neste contexto de profunda mudança ideológica, cultural, social e profissional, aponta-se a educação como cerne do desenvolvimento econômico, acrescido a uma melhor qualidade de vida. Neste mundo de maravilhas, vive-se também o risco de uma incerteza. E nessa complexidade, desenvolvem-se novas racionalidades, cujos primeiros sinais começam a emergir no século XX.

Compete-nos interpretar na atualidade os sinais emergentes do porvir para o qual estamos preparando as gerações, cuja formação a sociedade, em parte, quis confiar aos que se dedicam na instituição de ensino, de maneira especial.

Quando estas instituições, de maneira especial, organizam contextos de aprendizagem, exigentes e estimulantes, isto é, ambientes formativos que favoreçam o cultivo de atitudes saudáveis e o desabrochar das capacidades de cada um, com vista ao desenvolvimento das competências que lhes permitam viver em sociedade, esperam nela conviver e intervir em interação com os outros cidadãos. Tendo, como adquirido, que aprendizagem é um processo continuado de construção de experiência e saber e que a Instituição de Ensino Superior tem uma função curricular a desempenhar, considera-se o currículo como guia orientador de aprendizagem e atribui-se a estas instituições, em geral e a cada uma em particular, a gestão estratégica e flexível desse enquadramento orientador.

Caso seja proposto um processo em que cada membro da comunidade acadêmica seja provocado a refletir, os membros terão motivação para continuar a aprender e para investigar, reconhecerão a importância das dimensões afetivas e cognitivas do ser humano e reagirão melhor em face da mudança e do risco que caracteriza uma sociedade em profunda transformação.

É notável a evolução dos paradigmas investigativos e há consciência também de que a presença da investigação nas questões educativas é uma característica da atualidade e uma necessidade sentida, embora nem sempre 
assumida. Portanto, a mudança, no processo amplo da educação, é paradigmática. É preciso refletir sobre a vida que se vive, em uma atitude de diálogo com os problemas e as frustrações, os sucessos e os fracassos, mas também dialogar com o pensamento, o pensamento próprio e os dos outros.

As instituições assemelham-se às pessoas, são sistemas abertos, estão em permanente interação com o ambiente que as cerca, que e as estimula ou condiciona e dão contextos de aprendizagem. Uma organização inflexível, com uma estrutura excessivamente hierarquizada, silenciosa do diálogo entre setores, cética em relação às potencialidades dos seus membros, descendentemente pesada em todas as suas estratégias, estará fadada ao insucesso.

O desafio, portanto, não é aprender a aprender, mas aprender a desaprender, para reaprender e empreender de forma diversa e qualitativamente diferente, com base em métodos, estratégias, conteúdos e formas de organização, gestão e avaliação distintos. É a construção do novo conhecimento e da nova aprendizagem e sua transformação em conhecimento pedagógico nos sistemas de formação que, na realidade, impõe-se progressivamente.

É preciso ter a clareza de que a formação dessa consciência coletiva é um processo histórico que impulsiona a transformação da ação-reflexãocriação coletiva, em um contexto determinado em que há embate de idéias convergentes e divergentes e, por certo, a organização educacional consiste em um desses contextos.

Tudo isto é revelado por meio do projeto político-pedagógicocurricular, que significa a criação de uma verdadeira obra da comunidade educacional, enraizada no chão da instituição, explicitando uma concepção reflexiva e emancipatória da proposta desenvolvida neste espaço. A dimensão pedagógica deste projeto reside na intencionalidade institucional para desenvolver ações, a fim de cumprir sua finalidade de formar cidadãos nas dimensões sociocultural, política, profissional e humana. Na essência, a dimensão pedagógica da instituição, reflexiva e emancipatória, está na formação continuada dos diversos membros da comunidade.

De maneira especial, nestes tempos em que a sociedade informacional requer uma educação intercultural, quanto aos conhecimentos e aos valores, permanece a vontade de corrigir a desigualdade das situações e das oportunidades, já que a educação não é de forma alguma neutra.

Considera-se que a pós-modernidade não é um discurso da "nova" sociedade pós-industrial ou da "nova" sociedade da informação e do conhecimento, mas compreende "uma modificação sistêmica da própria sociedade capitalista, uma realidade superdeterminada pelas modificações das relações técnicas e relações sociais de produção do próprio capitalismo" que expressa a contraditória lógica cultural do capitalismo. 
As Universidades devem buscar a interação e evitar o desequilíbrio que hoje favorece marcadamente as ciências e tecnologias. Isso pode significar que muitas instituições tenham que priorizar temporariamente a área de ciências sociais, artes e humanidade, não porque devam ser consideradas mais importantes, mas para que voltem a ser socialmente reconhecidas como produções humanas de indiscutível valor na construção da história. Caso de fato estas instituições tematizem a sua função formativa, na formação de pessoal de nível superior, deve ser levada em conta à significação social dos conhecimentos e habilidades como um dos importantes critérios da qualidade acadêmica. Trata-se de construir criticamente os conhecimentos, de buscar novas formas de responder problemas específicos da realidade, entre as quais se coloca em evidência a presença dos estudantes na inserção do mundo atual, desta forma é estabelecida uma nova evangelização.

\section{Espaços imaginados e/ou inimaginados!}

Uma Universidade comunitária é instituída para participar com a sociedade na construção da mesma, portanto, tão importante quanto o ensino em si está a aprendizagem, a formação integral e os benefícios produzidos em prol da população. Dentro deste entendimento e contexto é que sentimos a formação, a investigação e a extensão em uma Universidade Católica.

A proposição de programas sistemáticos é entendida como uma atitude de abertura da instituição para a comunidade. O propósito central desta prática é elevar o padrão de vida social, cultural e familiar da população mais carente e, conseqüentemente, a melhoria geral da sociedade.

Com certeza, é um engano pensar que a obrigação de uma Instituição de Ensino Superior se restringe a dar aos seus estudantes uma boa formação intelectual e profissional. A sociedade não precisa apenas de profissionais competentes, bem preparados para enfrentar o mercado de trabalho, que por sinal se encontra cada vez mais exigente. Urge, também, sobretudo, a formação de cidadãos conscientes e solidários.

Não basta falar em cidadania e insistir na formação deste indivíduo. A universidade é o local preparado para a proposição das mentes e dos corações das novas gerações. Ela não pode perder a chance de imprimir a sua marca no cidadão, no profissional que receberá o seu documento de registro profissional.

O que significa dizer às Instituições de Ensino Superior é que, além de procurar oferecer informações, elas são desafiadas a oferecer a formação que permita a releitura da sociedade, do contexto, da história. O novo, a transformação do status é a construção de um futuro melhor para todos, que 
sempre forma preocupações na juventude. Seria menosprezar os jovens de hoje e imaginar que eles tenham se tornado acomodados. Seria diminuí-los e não acreditar no seu entusiasmo e no seu potencial. Seria, sobretudo, uma lástima não oferecer essa oportunidade.

A Conferência Mundial sobre o Ensino Superior, ocorrida em 1998 (Paris), recorda que a missão das instituições do Ensino Superior é de educar, formar e realizar pesquisas, e de forma particular contribuir para o desenvolvimento sustentável e o melhoramento da sociedade como um todo. Estas Instituições devem ser preservadas, reforçadas ainda mais, a fim de educar e formar pessoas altamente qualificadas, cidadãos responsáveis, capazes de entender as necessidades de todos, em todos os aspectos da atividade humana, oferecendo-lhes qualificações relevantes, incluindo capacitação profissional, nas quais sejam combinados conhecimentos teóricos e práticos de alto nível, mediante cursos e programas que se adaptem constantemente às necessidades presentes e futuras da sociedade.

É preciso promover um espaço aberto de oportunidades para o ensino superior e para a aprendizagem permanente, oferecendo uma ampla gama de opções e a possibilidade de alguns pontos flexíveis de ingresso e conclusão dentro do sistema. Assim como é preciso oportunizar a realização individual e mobilidade social, de modo a educar para a cidadania e a participação plena na sociedade com abertura para o mundo, visando a construir capacidades endógenas e consolidar os direitos humanos, o desenvolvimento sustentável, a democracia e a paz, em um contexto de justiça.

Espera-se promover, gerar e difundir conhecimento, por meio da pesquisa, e, como parte de sua atividade de extensão à comunidade, oferecer assessorias relevantes para ajudar as sociedades em seu desenvolvimento cultural, social e econômico, promovendo e desenvolvendo a pesquisa científica e tecnológica, assim como os estudos acadêmicos nas ciências sociais e humanas, e a atividade curativa nas artes.

Estima-se contribuir para a compreensão, interpretação, preservação, reforma, fomento e difusão das culturas nacionais e regionais; internacionais e históricas em um contexto de pluralismo e diversidade cultural; a fim de contribuir na proteção e consolidação dos valores da sociedade, formando a juventude de acordo com os valores nos quais se baseia a cidadania democrática, e proporcionadas perspectivas críticas e independes, a fim de colaborar no debate sobre as opções estratégicas e no fortalecimento de perspectivas humanistas. Além disso, é preciso contribuir para o desenvolvimento e melhoria da educação em todos os níveis, em particular por meio da capacitação de pessoal docente.

A relevância da educação superior deve ser avaliada em termos do ajuste entre o que a sociedade espera das instituições e o que elas realizam. 
Isto requer padrões éticos, imparcialidade política, capacidade crítica e, ao mesmo tempo, articulação melhor com os problemas da sociedade e do mundo do trabalho, com base em orientações, objetivos e necessidades sociais, incluindo o respeito às culturas e à proteção do meio ambiente. A preocupação deve ser a de facilitar o acesso a uma educação geral, ampla, especializada e freqüentemente interdisciplinar para determinadas áreas, focalizando-se nas habilidades e aptidões que preparem os indivíduos tanto para viver em uma diversidade de situações como para poder reorientar suas atividades.

A educação superior deve reforçar o seu papel de serviços extensivo à sociedade, especialmente as atividades voltadas para a eliminação da pobreza, intolerância, violência, analfabetismo, fome, deterioração do meio ambiente e enfermidades, principalmente por meio de uma perspectiva interdisciplinar e transdisciplinar para análise dos problemas e questões levantadas. Finalmente, a educação superior deve almejar a criação de uma nova sociedade não-violenta e não-opressiva, constituindo-se de indivíduos altamente motivados e íntegros, inspirados pelo amor à humanidade e guiados pela sabedoria e o bom senso.

As instituições de educação superior têm que educar estudantes para que sejam cidadãos bem informados e profundamente motivados, capazes de pensar criticamente e de analisar os problemas da sociedade, de procurar soluções aos problemas da sociedade e de aceitar responsabilidades sociais.

Para alcançar estas metas, podem ser necessárias reformas curriculares, com a utilização de novos e apropriados métodos, que permitam ir além do domínio cognitivo das disciplinas. Novas aproximações didáticas e pedagógicas devem ser acessíveis e promovidas, a fim de facilitar a aquisição de conhecimentos práticos, competências e habilidades para a comunicação, análise criativa e crítica, a reflexão independente e o trabalho em equipe em contextos multiculturais, em que a criatividade também envolva a combinação entre o saber, tradicional ou local, e o conhecimento aplicado da ciência avançada e da tecnologia.

Portanto, a compreensão de educação como mobilizador. O conceito de mobilização implica na idéia de movimento. Mobilizar é pôr em movimento; mobilizar-se é pôr-se em movimento. Para insistir nessa dinâmica interna é que utilizamos o termo de "mobilização", de preferência ao de "motivação". A mobilização implica mobilizar-se ("de dentro"), enquanto que a motivação enfatiza o fato de que se é motivado por alguém ou por algo ("de fora”). É verdade que, no fim da análise, esses conceitos convergem: pode-se dizer que eu me mobilizo para alcançar um objetivo que me motiva e que sou motivado por algo que pode mobilizar-me. Mas o termo mobilização tem a vantagem de insistir sobre a dinâmica do movimento.

Para ir além da idéia de movimento, mobilizar-se é reunir suas forças, 
para fazer uso de si próprio como recurso. Nesse sentido, a mobilização é, ao mesmo tempo, preliminar, relativamente a recursos em movimento. Mobilizarse é reunir suas forças, para fazer uso de si próprio como recurso. Nesse sentido, a mobilização é, ao mesmo tempo, preliminar, relativamente à ação e seu primeiro momento.

Neste processo, é fundamental o processo de reflexão na ação que tem uma função crítica, questionando as estruturas de pressupostos do ato de conhecer na ação. Na base dessa visão da reflexão, na ação do profissional, está uma visão construcionista da realidade, com a qual ele lida. Uma visão que nos leva a vê-lo construindo situações de sua prática, não apenas no exercício do talento profissional, mas também em todos os outros modos de competência profissional.

\section{Considerações}

Para as Universidades Católicas, que carregam o adjetivo católico, 0 compromisso social torna-se imperioso, uma vez que está impregnada de uma carga de comprometimento que nos foi legado há 2.000 anos.

Neste contexto, a Pastoral exerce um papel que transcende o próprio espaço físico da instituição em que está inserida. O mundo da Universidade está a exigir uma PASTORAL EVANGELIZADORA, de anúncio, de compromisso com a verdade, pela honestidade científica, pela preparação de profissionais competentes, para o mundo do trabalho, asseguradora da ética nas relações que vão se estabelecer no processo do evangelizar mediante o diálogo entre a fé, a ciência e a cultura.

Diante deste contexto, afirmamos que a educação pode ser vista como um grande laboratório da racionalidade, mas é mais realista vê-la como um contexto, na qual pessoas jovens aprendem a usar a razão para que possam crescer e se tornar cidadãos, companheiros e pais capazes de raciocinar. 0 conhecimento, que é o produto acabado do processo de investigação, é logicamente organizado e o aluno deve ser educado para procurar esta organização, para que nenhuma asserção seja feita sem prova, nenhuma opinião proferida sem as razões que acompanham e nenhum julgamento feito sem os critérios adequadamente relevantes.

O modelo reflexivo é, na realidade, totalmente social e comunitário. Seu objetivo é articular as diferenças causadas por atritos na comunidade, desenvolver argumentos para sustentar as reivindicações procedentes para, então, por meio de deliberação, obter uma compreensão de um quadro mais amplo que permitirá um julgamento mais objetivo. Em um universo pluralista, composto de comunicação diversificada, algumas das quais se sobrepõem às 
outras ou estão contidas dentro de outras, em que cada uma possui práticas, algumas das quais são locais e específicas e outras universais, torna-se cada vez mais importante articular e especificar o que precisamente está sendo traduzido para o quê e o que está sendo convertido para o quê. É impossível ter uma ética, ou política de distribuição, a menos que estejamos certos acerca dos valores ou significados contidos nas transações, nas quais estamos envolvidos.

Uma criança aprende sua primeira língua no seio da vida familiar e raramente é treinada na gramática ou no emprego correto das palavras. Ela se encontra envolvida em uma série de situações, em que cada qual possui sua qualidade única com seu significado próprio. Cada contexto estabelece seu significado e estes significados somam-se aos atos da fala e linguagem utilizadas nesses contextos. Separar tais atos dos seus contextos é separá-los dos seus significados, o que não é recuperado por meio da repetição monótona. Quando o significado é mínimo, o treinamento é justificável, mas quando o componente do significado é importante - e esta é, assim esperemos, a situação desejada - o treinamento é contraprodutivo, pois implica na dissociação do processo de pensar, a partir dos significados que, do contrário, talvez tivéssemos que pensar a respeito. A inteligência produzida por exercícios de repetição será provavelmente uma inteligência alienada.

O que recorda no ideal de educação platônica de formar indivíduos participantes e atuantes em uma comunidade. O mais importante é o ideal de sociedade, de Estado e, a partir desse ideal, será formado o indivíduo como tal.

Posteriormente, com o advento da modernidade, o acento educacional prioriza o indivíduo, como ser de autonomia e liberdade, deixando um pouco de lado a superinfluência da sociedade e da coletividade.

O desafio é como educar o indivíduo autônomo e livre, em harmonia com o cidadão participante e atuante na sociedade e a pensar em uma educação integral, que supere os unilateralismos de nossos sistemas educacionais. Isso implica em formar o homem em todas as suas dimensões e não somente nas dimensões intelectuais. Parece-nos insuficiente educar apenas o indivíduo competente e capaz de competir e fazer parte do mercado de trabalho. Urge, também, e, sobretudo, educar e formar um homem ético, participante de uma comunidade humana e, como tal, incidente na sua realidade social, transformando-a.

De Parmênides, Platão herdou a crença de que toda mudança é ilusória, visto que a realidade é imutável, eterna e intemporal. De Heráclito assimilou a doutrina do eterno fluir das coisas: Tudo flui e nada que existe, existe para sempre'. E, de Sócrates, aprendeu a debruçar-se sobre questões e problemas éticos.

Na educação, e por ela, o homem não somente assume uma condi- 
ção de abertura ao novo, mas, sobretudo, supera a si mesmo, atualiza suas capacidades e potencialidades. Por isso, a tarefa primeira da educação é a humanização. Educar um homem implica em ajudá-lo a tornar-se humano.

O homem é um conjunto de forças, ora conciliatórias, ora contraditórias. Por vezes, não é fácil harmonizar a complexidade dos impulsos humanos. O ser humano experimenta dentro de si forças estranhamente desencontradas. De um lado, é atraído para o alto, para o absoluto; num outro momento, experimenta sua contingência, deliciando-se com a limitação inerente a qualquer criatura.

O educador é aquele que provoca o educando, forçando a sua participação, o que supõe uma reeducação: abandono do "bem-estar" do mundo das sombras, portanto, da ignorância, para o mundo da realidade. Todo esse processo educativo poderá ser dolorido, pois exige esforço e provoca mudanças. A experiência humana mostra que se abrir à novidade da realidade, por vezes, não é uma tarefa fácil. Contemplar a verdade dos objetos iluminados pela luz do sol exige um preço a ser pago: desacomodar-se. Como dizíamos acima, outro aspecto importante que aparece no mito da caverna é que a educação consiste numa ocasião. O educador é aquele que cria ocasiões que possibilitam o conhecimento e a superação de seu educando. Toda ocasião tem o caráter de ser terapêutica, ou seja, um remédio para curar a ignorância. O conhecimento, obra da educação, é fruto de um deslumbramento.

Viver sempre será um risco e uma possibilidade de superação. É necessário ter coragem e audácia. O homem que não busca a verdade, e especialmente não procura a sua verdade, estará condenado a cometer sempre o mesmo erro. A frase do templo de Delfos "conhece-te a ti mesmo" será sempre um eco filosófico e ao mesmo tempo um clamor para aqueles que pretendem investir e gastar suas energias na educação. Construir no homem 0 verdadeiro e autêntico homem exige constante e incansável dedicação.

O homem é um ser aberto, voltado para o exterior. Essa capacidade de abertura possibilita o homem a conhecer-se a si mesmo. Abrir-se implica viver em uma comunidade, visto que a convivência comunitária é imprescindível. O homem sozinho e isolado tende a fechar-se sobre si mesmo. Neste sentido, a experiência nos tem mostrado, e Platão já sabia muito bem, que todo narcisismo é suicida, pois mata a si mesmo.

Ao procurar compreender todo este percurso do ser humano, a Universidade é convocada a atuar efetivamente, com intensidade e intencionalidade, como espaço formador, de tal forma que ao compreender a pastoral com os universitários, precisa sair de seu mundo para voltar-se diretamente à sociedade. É realmente de grande valor a experiência do trabalho social, motivada por um apelo existencial ou motivada pela fé. A oportunidade do SERVIÇO, principalmente quando ele pode aplicar seus conhecimentos específicos, pode 
ser inclusive uma oportunidade de conversão, diante de realidades que propõem questionamentos fortes sobre o sentido da vida, a fim de construir situações inimaginadas, mas que somente uma comunidade ativa e participativa poderá propor e empreender, inclusive evangelizar.

\section{Referências}

ASSOCIAÇÃO BRASILEIRA DE ESCOLAS SUPERIORES CATÓLICAS. A universidade católica no mundo de hoje. Belo Horizonte: ABESC, 1973.

JOÃO PAULO II. Discurso ao "Institut Catholique de Paris", $1^{\circ}$ de junho de 1980: Insegnamenti di Giovanni Paolo II, vol. III/1 (1980), p. 1581.

JULATTO, Clemente Ivo. A Educação na PUCPR a serviço da vida e do Futuro. Curitiba: PUCPR, 1998. Mineo.

UNESCO. Conferência Mundial sobre a Educação Superior. Declaração mundial sobre Educação Superior no Século XXI: Visão e Ação. Marco Referencial de AÇÃO Prioritária para a Mudança e o desenvolvimento da Educação Superior (Paris, 1998). Piracicaba: UNIMEP, 1998. 